\begin{tabular}{|c|c|}
\hline Title & Divergent synthesis of kinase inhibitor derivatives, leading to discovery of selective Gck inhibitors \\
\hline Author(s) & $\begin{array}{l}\text { Matsumaru, T akanori; I nai, Makoto; I shigami, Kana; I wamatsu, Toshiki; Maita, Hiroshi; Otsuguro, Satoko; Nomura, } \\
\text { T akao; Matsuda, A kira; Ichikawa, Satoshi; Sakaitani, Masahiro; Shuto, Satoshi; Maenaka, Katsumi; Kan, T oshiyuki }\end{array}$ \\
\hline Citation & $\begin{array}{l}\text { Bioorganic \& medicinal chemistry letters, 27(10), 2144-2147 } \\
\text { https://doi.org/10.1016/.bmcl.2017.03.055 }\end{array}$ \\
\hline Issue Date & 2017-05-15 \\
\hline Doc URL & http:/hdl.handle.net/2115/74002 \\
\hline Rights & $\begin{array}{l}\text { (C2017. This manuscript version is made available under the CC-BY-NC-ND } 4.0 \text { license } \\
\text { http://creativecommons.org/icenses/by-nc-nd/4.0/ }\end{array}$ \\
\hline Rights(URL) & http://creativecommons.org/icenses/by-nc-nd/4.0/ \\
\hline Type & article (author version) \\
\hline File Information & WoS_79283_matsumaru.pdf \\
\hline
\end{tabular}

Instructions for use 


\section{Graphical Abstract}

To create your abstract, type over the instructions in the template box below.

Fonts or abstract dimensions should not be changed or altered.

\section{Divergent synthesis of kinase inhibitor derivatives, leading to discovery of selective Gck inhibitors}

Takanori Matsumaru, Makoto Inai, Kana Ishigami, Toshiki Iwamatsu, Hiroshi Maita, Satoko Otsuguro, Takao Nomura, Akira Matsuda, Satoshi Ichikawa, Masahiro Sakaitani, Satoshi Shuto, Katsumi Maenaka and Toshiyuki Kan
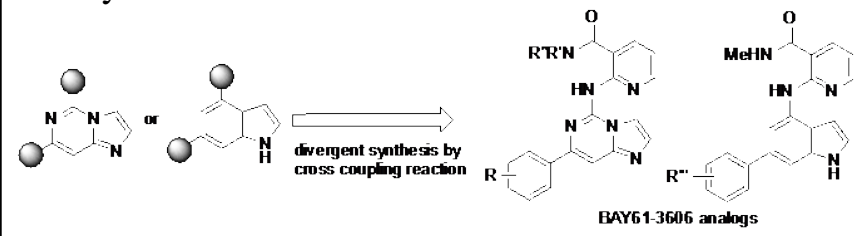

Leave this area blank for abstract info.

AY61-3606 anabogs 


\title{
Divergent synthesis of kinase inhibitor derivatives, leading to discovery of selective Gck inhibitors
}

\author{
Takanori Matsumaru $^{\mathrm{a}}{ }^{\dagger}$, Makoto Inai ${ }^{\mathrm{b} \dagger}$, Kana Ishigami ${ }^{\mathrm{b}}$, Toshiki Iwamatsu ${ }^{\mathrm{a}}$, Hiroshi Maita ${ }^{\mathrm{a}}$, Satoko \\ Otsuguro ${ }^{a}$, Takao Nomura ${ }^{a}$, Akira Matsuda ${ }^{a}$, Satoshi Ichikawa ${ }^{a}$, Masahiro Sakaitani ${ }^{a}$, Satoshi Shuto ${ }^{\text {, }}$ \\ Katsumi Maenaka $^{\mathrm{a}}{ }^{*}$ and Toshiyuki Kan ${ }^{\mathrm{b}}$ * \\ ${ }^{a}$ Faculty of Pharmaceutical Sciences, Hokkaido University, Kita-12, Nishi-6, Kita-ku, Sapporo 060-0812, Japan \\ ${ }^{\mathrm{b}}$ School of Pharmaceutical Sciences, University of Shizuoka, 52-1 Yada, Suruga-ku, Shizuoka 422-8526, Japan
}

\section{ARTICLE INFO}

Article history:

Received

Revised

Accepted

Available online

Keywords:

BAY 61-3606

Imidazo[1,2-c]pyrimidine

Gck

Indole

Kinase inhibitor

\section{ABSTRACT}

We accompished divergent synthesis of potent kinase inhibitor BAY 61-3606 (1) and 27 derivatives via conjugation of imidazo[1,2-c]pyrimidine and indole ring compounds with aromatic (including pyridine) derivatives by means of palladium-catalyzed cross-coupling reaction. Spleen tyrosine kinase (Syk) and germinal center kinase (Gck, MAP4K2) inhibition assays showed that some of the synthesized compounds were selective Gck inhibitors.

2009 Elsevier Ltd. All rights reserved.
During our investigations of protein kinase inhibitors, ${ }^{1,2}$ we became interested in BAY 61-3606 (1), which is an ATPcompetitive, reversible, selective protein kinase inhibitor. It was originally employed as a potent, orally available spleen tyrosine kinase (Syk) inhibitor. ${ }^{3}$ It was reported to attenuate the proliferation of retinoblastoma cells ${ }^{4}$ and B-cell leukemia cells, ${ }^{5}$ and has been utilized to examine chemomigration of nasopharyngeal carcinoma cells. ${ }^{6}$ A pre-clinical study showed that BAY 61-3606 also reduces the viability of colon cancer cells by inhibiting germinal center kinase (Gck, MAP4K2), ${ }^{7}$ a member of the serine/threonine protein kinase family. Although the biological functions of Gck are not yet well understood, it may work as a regulator of NFK $\beta$ to modulate UV-induced apoptosis of melanoma cells. ${ }^{8}$ To investigate the biological functions of Gck in detail, selective inhibitors of Gck are required.

Here, we focused on BAY 61-3606 (1) as a lead compound for selective Gck inhibitors. Generally, the hinge region, DFG loop, gatekeeper residue and hydrophobic pocket of protein kinases are essential features of the binding sites of most ATPcompetitive protein kinase inhibitors. ${ }^{9}$ However, the binding modes of $\mathbf{1}$ to Syk and Gck are unknown. Therefore, we set out to synthesize a series of inhibitor candidates and to explore their structure-activity relationships towards these kinases. We planned to develop two synthetic strategies, one for modification of the substituted benzene moiety at the 7-position and the other

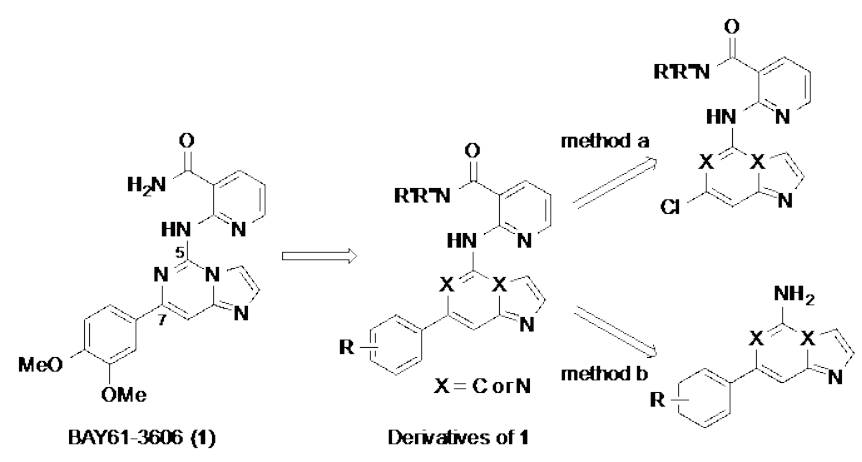

Scheme 1. Structure of BAY 61-3606 (1) and its derivatives.

\footnotetext{
* Corresponding author. Tel.: +81-1-1-706-3970; fax: +81-1-1-706-4986; e-mail: maenaka@pharm.hokudai.ac.jp

* Corresponding author. Tel.: +81-5-4-264-5746; fax: +81-5-4-264-5745; e-mail: kant@u-shizuoka-ken.ac.jp

$\dagger$ These authors equally contributed to this work.
} 
for modification of the amide moiety and imidazo[1,2c]pyrimidine moiety (Scheme 1).We considered that a divergent synthetic approach to derivatives of $\mathbf{1}$ would allow us to quickly identify candidates for further elaboration. For this purpose, we anticipated that cross-coupling reactions would be a reliable method to incorporate various functional groups. Thus, we planned a synthetic strategy based on conjugation of imidazo[1,2-c]pyrimidine and indole ring compounds with aromatic (including pyridine) moieties by means of palladiumcatalyzed cross-coupling reaction for the generation of diverse BAY 61-3606 derivatives. The resulting 5,7-disubstituted imidazo[1,2-c]pyrimidine derivatives and indole derivatives were assayed for Syk- and Gck-inhibitory activities.

We first explored replacement of the dimethoxybenzene moiety in BAY 61-3606, as shown in Scheme 2. The imidazo[1,2-c]pyrimidine skeleton of $\mathbf{3}$ was constructed by condensation of tri-substituted pyrimidine $\mathbf{2}$ with bromoacetaldehyde dimethyl acetal. ${ }^{10}$ After hydrolysis of the thiomethyl group, chloridation of the resulting hydroxy group furnished 5,7-dichloroimidazo[1,2-c]pyrimidine (4). While aniline derivatives could be reacted with $\mathbf{4}$ at the 5-position by means of Haigis' method ${ }^{7}$ that heating with $\mathbf{4}$ and anilines in solvent, the amino-nicotinic ester could not be incorporated.
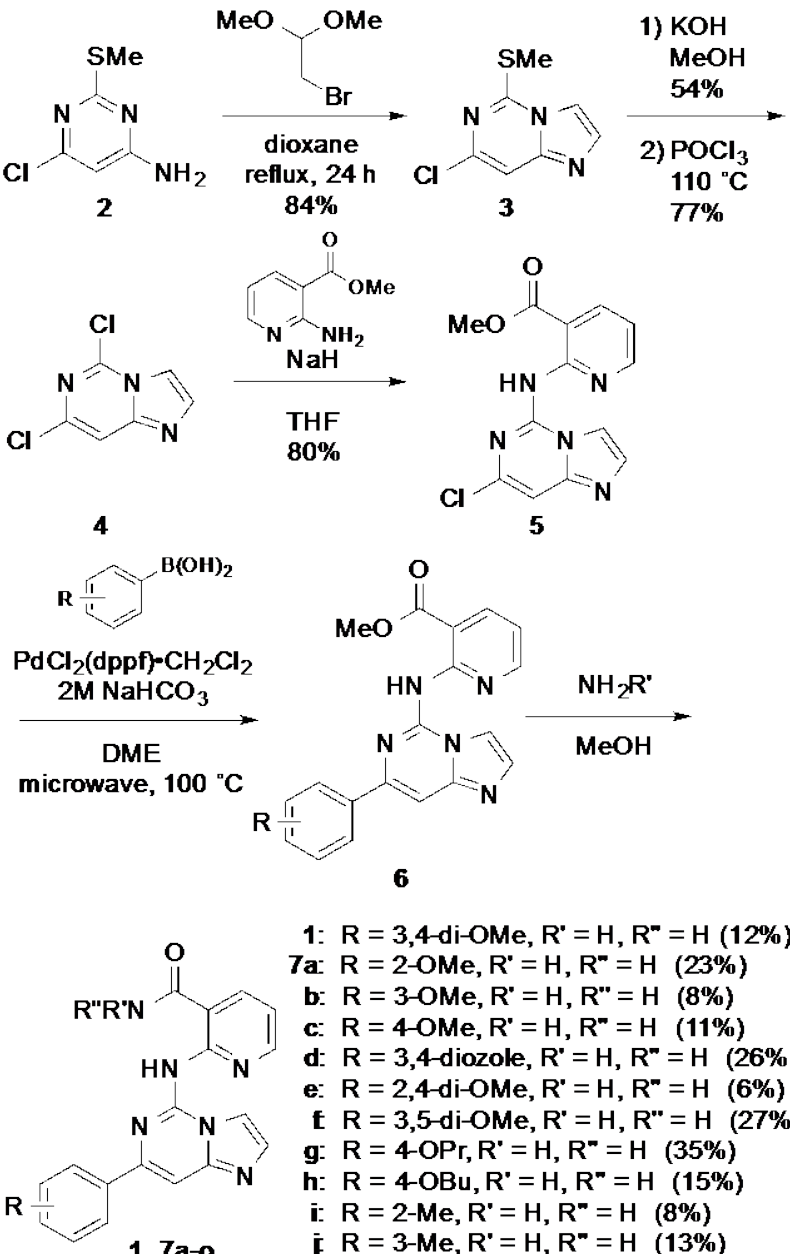

1: $R=3,4$-di-OMe, $R^{*}=H, R^{\prime \prime}=H(12 \%)$

7a: $R=2$-OMe, $R^{\prime \prime}=H, R^{\prime \prime}=H(23 \%)$

b: $R=3-O M e, R^{\prime \prime}=H, R^{\prime \prime}=H(8 \%)$

c: $R=4-O M e, R^{\prime}=H, R^{\prime \prime}=H(11 \%)$

d: $R=3,4$-diozole, $R^{\prime}=H, R^{*}=H(26 \%)$

e: $R=2,4$-di-OMe, $R^{\prime \prime}=H, R^{\prime \prime}=H(6 \%)$

f $\mathrm{R}=3,5$-di-OMe, $\mathrm{R}^{\prime}=\mathrm{H}, \mathrm{R}^{\prime \prime}=\mathrm{H}(27 \%)$

g: $R=4-O P r, R^{*}=H, R^{*}=H(35 \%)$

h: $R=4-O B u, R^{*}=H, R^{\prime \prime}=H(15 \%)$

i: $R=2-M e, R^{\prime}=H, R^{\prime \prime}=H(8 \%)$

F $R=3-M e, R^{\prime \prime}=H, R^{\prime \prime}=H(13 \%)$

k $R=4-M e, R^{\prime}=H, R^{\prime \prime}=H(18 \%)$

I: $R=3-O M e, R^{*}=H, R^{\prime \prime}=\operatorname{Me}(7 \%)$

m: $R=4-O M e, R^{\prime}=H, R^{\prime \prime}=$ Me $(20 \%)$

n: $R=3,4$-di-OMe, $R^{\prime \prime}=H, R^{\prime \prime}=$ Me $(14 \%)$

o: $R=3,4$-diozole, $R^{*}=H, R^{*}=\operatorname{Me~}(20 \%)$

* over 2 steps yields from 5

Scheme 2. Synthesis of BAY 61-3606 and its derivatives via 5,7dichloroimidazo[1,2-c]pyrimidine (4).
To obtain the desired common intermediate 5, treatment of $\mathbf{4}$ with 2-amino-3-methoxycarbonylpyridine under basic conditions was adopted, affording 5 in $80 \%$ yield. Although the palladiumcatalyzed amination of $\mathbf{4}$ also proceeded, the chemical yield of $\mathbf{5}$ was relatively low (data not shown). For the preparation of 1, microwave-assisted Suzuki-Miyaura coupling reaction with 3,4dimethoxyphenylboronic acid was employed to obtain 6. Finally, ammonolysis of $\mathbf{6}$ gave the desired $\mathbf{1}$ in 12\% yield over 2 steps. This protocol was utilized for the preparation of several derivatives $\mathbf{7 a - 0}$.

Although the synthetic method illustrated in Scheme 2 could incorporate various aromatic rings at the 7-position of the imidazopyridine ring, incorporation at the 5-position was limited in 2-aminonicotinamide derivatives. Thus, we focused on developing an alternative synthetic method for the imidazo[1,2c]pyrimidine ring in 1, as shown in Scheme 3. Treatment of 2methylimidazole $\mathbf{8}$ with excess benzoyl chloride was effective for the acylation reaction. Without purification of the crude products, acidic hydrolysis provided $C$-acylated methylimidazoles $9 \mathbf{9 a}, \mathbf{b}$ exclusively. Since this acylation reaction could be carried out with several other acyl chlorides, this protocol was expected to be suitable to prepare the corresponding derivatives. Construction of the pyrimidine ring was performed by treatment of 9a with cyanamide under heating to give 10a. Subsequently, microwaveassisted Buchwald-Hartwig coupling ${ }^{11,12}$ of 10a and 2bromopyridine derivative provided the BAY 61-3606 framework $11 a$.

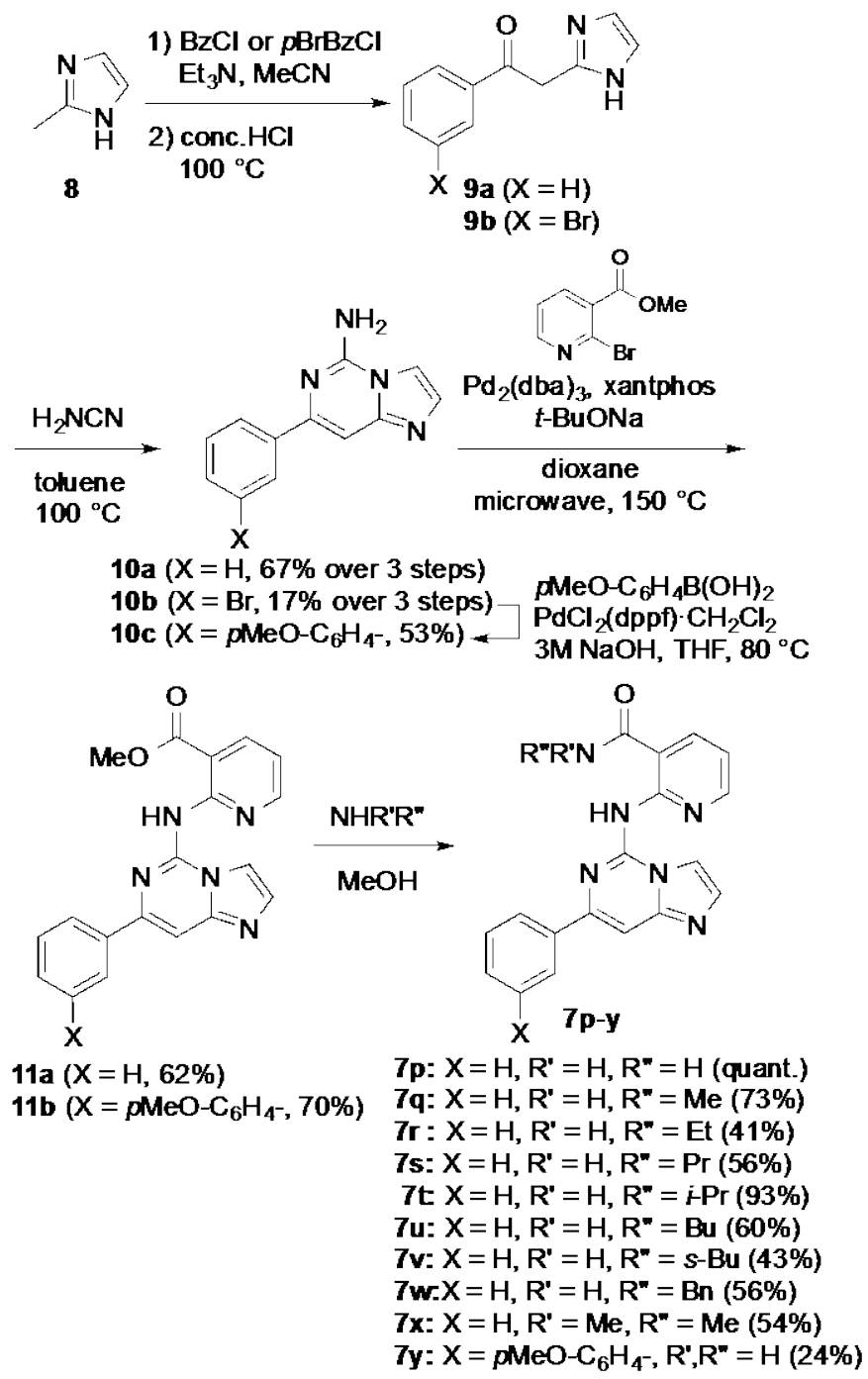

Scheme 3. Alternative synthesis of BAY 61-3606 derivatives. 
Ammonolysis of 11a proceeded with several amines to give amide derivatives $\mathbf{7 p - x}$. Since Pd-mediated cross-coupling reactions can proceed with various aromatic halides, this protocol should be also applicable to generate diverse BAY 61-3606 analogues. Employment of $m-\mathrm{BrBzCl}$ with 8 provided $10 \mathbf{b}$ via a procedure similar to that used to prepare 10a. Bromide 10b can undergo additional cross-coupling reaction, and Suzuki-Miyaura coupling of 10b with $p$-methoxyphenylboric acid provided 10c. Subsequently, ammonolysis of 10c also proceeded smoothly to give $7 \mathbf{y}$.

Next we turned our attention to replacement of the core skeleton of $\mathbf{1}$ from the imidazo[1,2-c]pyrimidine ring to an indole. Since many drugs contain indole structures, development of a versatile synthetic method would be potentially valuable. Thus, we planned to construct a platform strategy for the synthesis of indole derivatives as shown in Scheme 4. After regioselective bromination of 2,6-dinitrotoluene (12), indole structure was constructed by employing the Leimgruber and Batcho protocol. ${ }^{13,14}$ Following treatment of 4-bromo-2,6-dinitrotoluene (13) with DMF dimethylacetal and pyrrolidine, the desired alkylation reaction of $\mathbf{1 3}$ proceeded smoothly. Subsequently, $\mathrm{TiCl}_{3}$ mediated mono-selective reduction of the nitro group afforded the stable 6-bromo-4-nitroindole 14. The indole 14 served as a platform for subsequent stepwise cross-coupling reactions. Firstly, incorporation of an aromatic ring was performed by Suzuki-Miyaura coupling reaction. After reduction of the nitro group of 15, amination reaction under similar conditions to those employed in the synthesis of imidazopyrimidine derivatives in Scheme 2 gave 17. Since conversion of the aniline group to diazonium salt and subsequent cross coupling reaction could be readily carried out, 16a, b were also considered to be available as coupling precursors.
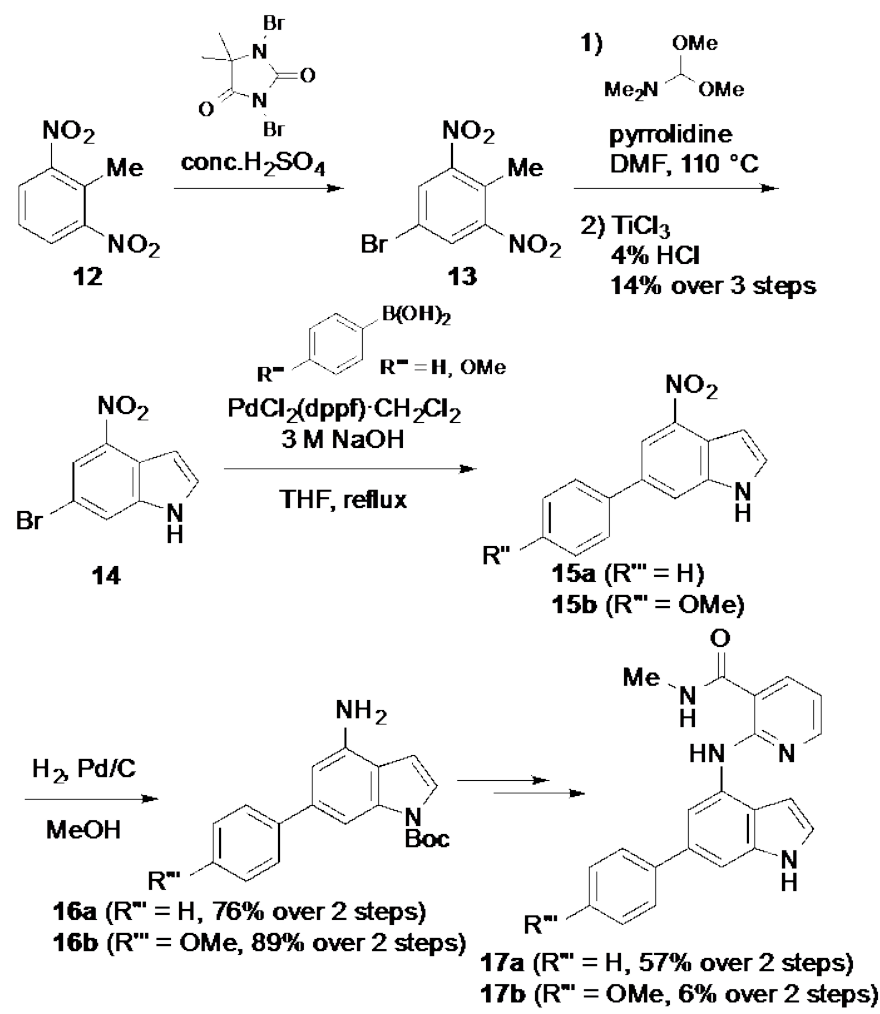

Scheme 4. Replacement the core skeleton from imidazo[1,2-c]pyrimidine to indole.

We next evaluated the Syk- and Gck-inhibitory activities of the synthesized BAY 61-3606 derivatives (Table 1). Specifically, we compared the ability of BAY 61-3606 derivatives at the concentration of $1 \mu \mathrm{M}$ to competitively inhibit binding of ATP to the active sites of these kinases. BAY 61-3606 (1) showed 85\% inhibition of Syk activity and 100\% inhibition of Gck activity. In addition, potent inhibition of both Syk and Gck was observed by $\mathbf{7 a}, \mathbf{7 c}, \mathbf{7 e}, \mathbf{7 f}, \mathbf{7 j}$, and $\mathbf{7 k}$. It is noteworthy that $\mathbf{7 p}$, which does not possess any substitution on the phenyl group at the 7-position of imidazo[1,2-c]pyrimidine, also showed potent inhibition of both kinases. Potent and selective Gck-inhibitory activity was observed with several other derivatives $(\mathbf{7 b} ; \mathrm{R}=3$-OMe, $\mathbf{7 d}$; $\mathrm{R}=$ 3,4-dioxole, 7i; $\left.\mathrm{R}=2-\mathrm{Me}, 7 \mathbf{y} ; \mathrm{R}=3-\left(p \mathrm{MeO}-\mathrm{C}_{6} \mathrm{H}_{4}\right)\right)$. Furthermore, the concentration dependency of the activity of these 4 compounds were measured, and $K_{\mathrm{d}} \mathrm{s}$ were determined to be 59 , 49, 100 and $220 \mathrm{nM}$, respectively. These results suggest that a benzene moiety with these $\mathrm{R}$ groups is important for the kinaseinhibitory activity. Introduction of a methyl group at the amide moiety, the resulting 7l-7o caused marked attenuation of the inhibitory activities towards both Gck and Syk. In derivatives that having various alkylamides, $\mathbf{7 q - 7 x}$, the inhibitory activities were completely abrogated. It is suspected that the amide moiety also plays a critical role in the interaction with both kinases. Indole derivative 17a showed selective Gck inhibition, although the activity was weak. Since 17a had decreased Syk-inhibitory activity compared to $\mathbf{7 q}$, the indole skeleton may play an important role in selective kinase inhibition.

Table 1 Inhibitory activity of BAY 61-3606 derivatives towards Syk and Gck.

\begin{tabular}{|c|c|c|c|c|c|}
\hline Compound & $\mathrm{R}$ & $\mathrm{R}^{\prime}$ & $\mathrm{R}^{\prime \prime}$ & Syk* & Gck* \\
\hline $\begin{array}{l}\text { BAY 61-3606 } \\
\text { (1) }\end{array}$ & 3,4-di-OMe & $\mathrm{H}$ & $\mathrm{H}$ & 85 & 100 \\
\hline $7 a$ & 2-OMe & $\mathrm{H}$ & $\mathrm{H}$ & 61 & 100 \\
\hline 7b & 3-OMе & $\mathrm{H}$ & $\mathrm{H}$ & 37 & 97.2 \\
\hline $7 \mathrm{c}$ & 4-OMe & $\mathrm{H}$ & $\mathrm{H}$ & 59 & 99.1 \\
\hline 7d & 3,4-dioxole & $\mathrm{H}$ & $\mathrm{H}$ & 24 & 94.3 \\
\hline $7 e$ & 2,4-di-OMe & $\mathrm{H}$ & $\mathrm{H}$ & 80 & 100 \\
\hline $7 f$ & 3,5-di-OMe & $\mathrm{H}$ & $\mathrm{H}$ & 80 & 100 \\
\hline $7 g$ & $4-\mathrm{OPr}$ & $\mathrm{H}$ & $\mathrm{H}$ & 51 & 86 \\
\hline $7 \mathrm{~h}$ & $4-\mathrm{OBu}$ & $\mathrm{H}$ & $\mathrm{H}$ & 4 & 47 \\
\hline $7 \mathbf{i}$ & 2-Me & $\mathrm{H}$ & $\mathrm{H}$ & 11 & 94.7 \\
\hline $7 \mathbf{j}$ & 3-Me & $\mathrm{H}$ & $\mathrm{H}$ & 74 & 100 \\
\hline $7 k$ & 4-Me & $\mathrm{H}$ & $\mathrm{H}$ & 58 & 99.2 \\
\hline 71 & 3-OMe & $\mathrm{H}$ & $\mathrm{Me}$ & 1 & 0 \\
\hline $7 \mathrm{~m}$ & 4-OMe & $\mathrm{H}$ & $\mathrm{Me}$ & 0 & 1 \\
\hline $7 n$ & 3,4-di-OMe & $\mathrm{H}$ & $\mathrm{Me}$ & 0 & 0 \\
\hline 70 & 3,4-dioxole & $\mathrm{H}$ & $\mathrm{Me}$ & 9 & 1 \\
\hline $7 \mathbf{p}$ & $\mathrm{H}$ & $\mathrm{H}$ & $\mathrm{H}$ & 73 & 99.5 \\
\hline $7 \mathbf{q}$ & $\mathrm{H}$ & $\mathrm{H}$ & $\mathrm{Me}$ & 30 & 24 \\
\hline $7 r$ & $\mathrm{H}$ & $\mathrm{H}$ & Et & 19 & 20 \\
\hline $7 \mathrm{~s}$ & $\mathrm{H}$ & $\mathrm{H}$ & $\operatorname{Pr}$ & 5 & 16 \\
\hline $7 t$ & $\mathrm{H}$ & $\mathrm{H}$ & $i-\operatorname{Pr}$ & 0 & 0 \\
\hline $7 u$ & $\mathrm{H}$ & $\mathrm{H}$ & $\mathrm{Bu}$ & 8 & 8 \\
\hline $7 v$ & $\mathrm{H}$ & $\mathrm{H}$ & $s-\mathrm{Bu}$ & 1 & 29 \\
\hline $7 w$ & $\mathrm{H}$ & $\mathrm{H}$ & $\mathrm{Bn}$ & 0 & 2 \\
\hline $7 \mathrm{x}$ & $\mathrm{H}$ & Me & $\mathrm{Me}$ & 10 & 58 \\
\hline $7 y$ & $3-\left(p \mathrm{MeO}-\mathrm{C}_{6} \mathrm{H}_{4}\right)$ & $\mathrm{H}$ & $\mathrm{Me}$ & 5 & 84 \\
\hline $17 \mathbf{a}$ & - & - & - & 1 & 29 \\
\hline $17 \mathrm{~b}$ & - & - & - & 0 & 2 \\
\hline
\end{tabular}

3606 derivatives at $1 \mu \mathrm{M}$ concentration.

Since addition of the bulky $p$-methoxyphenyl group in the phenyl imidazo[1,2-c]pyrimidine ring, such as $7 \mathbf{y}$, did not decrease the biological activity, this compound may be available as a probe molecule for chemical biology studies. We have previously accomplished the synthesis of several probe molecules by elongation and addition of aromatic rings to active compounds together with the use of a linker group and probe unit such as biotin and/or a fluorescent group. ${ }^{15-18}$ Further investigations to develop a probe molecule from $\mathbf{7 y}$ are currently underway in our laboratory. 
In summary, we have developed novel divergent synthetic routes to various imidazo[1,2-c]pyrimidine and indole derivatives related to BAY 61-3606. Among them $\mathbf{7 b}, \mathbf{7 d}, \mathbf{7 i}$, and $\mathbf{7 y}$ exhibited selective Gck inhibition. They may be suitable for the development of probes for studying the biological roles of Gck.

\section{Acknowledgments}

This research is (partially) supported by the Platform Project for Supporting in Drug Discovery and Life Science Research

(Platform for Drug Discovery, Informatics, and Structural Life Science ) from the Ministry of Education, Culture, Sports, Science (MEXT) and Japan Agency for Medical Research and development (AMED).

\section{Supplementary data}

Supplementary data associated with this article can be found, in the online version,

\section{Reference}

1. Sako, Y.; Ichikawa, S.; Osada, A.; Matsuda, A. Bioorg. Med. Chem. 2010, 18, 7878-7889.

2. Ichikawa, S.; Tatebayashi, N.; Matsuda, A. J. Org. Chem. 2013, 78, 12065-12075.

3. Yamamoto, N.; Takeshita, K.; Shichijo, M.; Kokubo, T.; Sato, M.; Nakashima, K.; Ishimori, M.; Nagai, H.; Li, Y.-F.; Yura, T.; Bacon, K. B. J. Pharmacol. Exp. Ther. 2003, 306, 1174-1181.

4. Zhang, J.; Benavente, C. A.; McEvoy, J.; Flores-Otero, J.; Ding, L.; Chen, X.; Ulyanov, A.; Wu, G.; Wilson, M.; Wang, J.; Brennan, R.; Rusch, M.; Manning, A. L.; Ma, J.; Easton, J.; Shurtleff, S.; Mullighan, C.; Pounds, S.; Mukatira, S.; Gupta, P.; Neale, G.; Zhao, D.; Lu, C.; Fulton, R. S.; Fulton, L. L.; Hong, X.; Dooling, D. J.; Ochoa, K.; Naeve, C.; Dyson, N. J.; Mardis, E. R.; Bahrami, A.; Ellison, D.; Wilson, R. K.; Downing, J. R.; Dyer, M. A. Nature 2012, 481, 329-334.

5. Perova, T.; Grandal, I.; Nutter, L. M. J.; Papp, E.; Matei, I. R.; Beyene, J.; Kowalski, P. E.; Hitzler, J. K.; Minden, M. D.; Guidos, C. J.; Danska, J. S. Sci. Transl. Med. 2014, 6, 236ra62.

6. Luangdilok, S.; Box, C.; Patterson, L.; Court, W.; Harrington, K.; Pitkin, L.; Rhŷs-Evans, P.; O-charoenrat, P.; Eccles, S. Cancer Res. 2007, 67, 7907-7916.

7. Lau, K. S.; Zhang, T.; Kendall, K. R.; Lauffenburger, D.; Gray, N. S.; Haigis, K. M. PLoS One 2012, 7, 1-9.

8. Ivanov, V. N.; Kehrl, J. H.; Ronai, Z. Oncogene 2000, 19, 933-942.

9. Zhang, J.; Yang, P.; Gray, N. Nat. Rev. Cancer 2009, 9, 28-39.

10. Barsanti, P. A.; Pan, Y.; Lu, Y.; Jain, R.; Cox, M.; Aversa, R. J.; Dillon, M. P.; Elling, R.; Hu, C.; Jin, X.; Knapp, M.; Lan, J.; Ramurthy, S.; Rudewicz, P.; Setti, L.; Subramanian, S.; Mathur, M.; Taricani, L.; Thomas, G.; Xiao, L. ACS Med.Chem.Lett. 2015, 6, 42-4.

11. Guari, Y.; Van Es, D. S.; Reek, J. N. H.; Kamer, P. C. J.; Van Leeuwen, P. W. N. M. Tetrahedron Lett. 1999, 40, 3789-3790.
12. Yin, J.; Zhao, M. M.; Huffman, M. A.; McNamara, J. M. Org. Lett. 2002, 4, 3481-3484.

13. Batcho, A. D.; Leimgruber, W. Org. Synth. 1985, 63, 214-220.

14. Bös, M.; Sleight, A. J.; Godel, T.; Martin, J. R.; Riemer, C.; Stadler, H. Eur. J. Med. Chem. 2001, 36, 165-178.

15. Asakawa, T.; Hiza, A.; Nakayama, M.; Inai, M.; Oyama, D.; Koide, H.; Shimizu, K.; Wakimoto, T.; Harada, N.; Tsukada, H.; Oku, N.; Kan, T. Chem. Commun. (Camb). 2011, 47, 2868-2870.

16. Yoshida, A.; Hirooka, Y.; Sugata, Y.; Nitta, M.; Manabe, T.; Ido, S.; Murakami, K.; Saha, R. K.; Suzuki, T.; Ohshima, M.; Yoshida, A.; Itoh, K.; Shimizu, K.; Oku, N.; Furuta, T.; Asakawa, T.; Wakimoto, T.; Kan, T. Chem. Commun. (Camb). 2011, 47, 1794-1796.

17. Hiza, A.; Tsukaguchi, Y.; Ogawa, T.; Inai, M.; Asakawa, T.; Hamashima, Y.; Kan, T. Heterocycles 2014, 88, 1371-1396.

18. Sasaki, S.; Suzuki, H.; Ouchi, H.; Asakawa, T.; Inai, M.; Sakai, R.; Shimamoto, K.; Hamashima, Y.; Kan, T. Org. Lett. 2014, 16, 564-567. 